\title{
STATISTICAL ANALYSIS OF MINERAL SOILS IN THE ODRA VALLEY
}

\author{
Magda Hudak, ARKadiusz RojnA ${ }^{1}$ \\ Zielona Góra University
}

\begin{abstract}
The aim of this article is to present the results of statistical analyses of laboratory experiment results obtained from an ITB ZW-K2 apparatus, Kamieński tubes and grain-size distribution curves. Beside basic statistical parameters (mean, sum, minimum and maximum), correlation analysis and multivariate analysis of variance at significance levels $\alpha<0.01$ and $\alpha<0.05$ were taken into account, as well as calculations of LSD confidence half-intervals.

The research material was collected from the valley of the Odra river near the town of Stubice in Lubuskie province. The research involved mineral, non-rock fine-grained, non-cohesive soils lying at the depth of $0.3-1.5 \mathrm{~m}$.
\end{abstract}

\section{AIMS AND AREA OF THE RESEARCH}

The aim of the research was to analyse variations in hydraulic conductivity $\left(k_{f}\right)$ of non-cohesive soils in the area of Lubusz Odra Gorge near the town of Stubice (Lubuskie province) (Fig. 1).

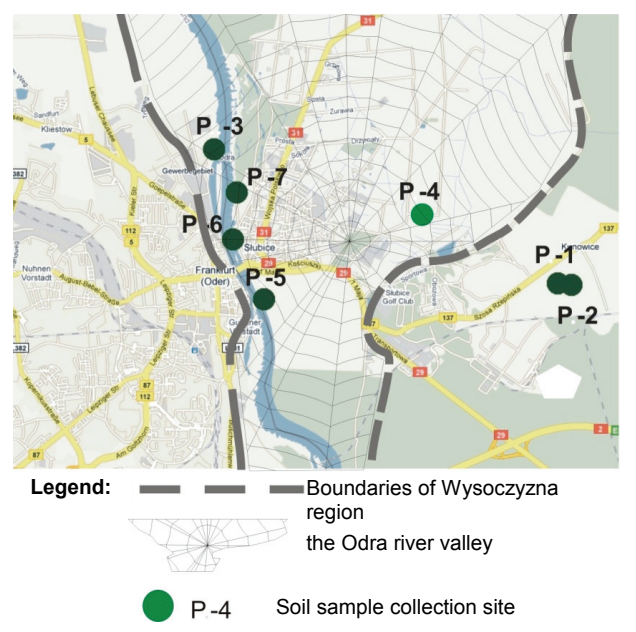

Fig. 1. Soil sample collection sites (Rojna and Błaszczyk [1])

\footnotetext{
${ }^{1}$ The author is a scholarship-holder in the framework of Submeasure 8.2.2 "Regional Innovation Strategies", Measure 8.2 "Knowledge Transfer", Priority VIII "Regional Human Resurces for Economy" Operational Programme Human Capital. The scholarship was co-funded by the EU European Social Fund and the Polish government.
} 
Between August 2009 and September 2010, a number of field and laboratory measurements were performed, resulting in taking 38 samples of non-cohesive mineral soils.

Hydraulic conductivity was investigated with field methods: Maag's method and submerging absorption pits (Kamieński's method) and with laboratory methods: grain-size analysis, Kamieński's tubes and ITB ZW-K2 apparatus. A number of measurements of water table changes and discharge of water flowing through soil samples were conducted in these systems: field measurements for soils with undisturbed structure and laboratory measurements for disturbed structure (Rojna and Błaszczyk [1]).

\section{RESULTS AND DISCUSSION}

The input data for statistical analysis were: grain size analysis results and the results of field and laboratory hydraulic conductivity measurements of soil samples $\mathrm{P}-1-\mathrm{P}-38$.

Investigation of relationships between the obtained soil hydraulic conductivity values and various spatial factors was conducted by means of linear correlation analysis between the hydraulic conductivity of all the analysed samples (P-1-P-38) and factors which can have an influence on these values (including grain size analysis). The results of linear correlation analysis between the hydraulic conductivity of the analysed samples and percentages of particular grain size fractions in the soils under study $\left(d_{i}<0.063-20.0 \mathrm{~mm}\right)$ are shown in Table 1.

Table 1

Linear correlation coefficients (Pearson's $r$ ) between hydraulic conductivity of soils determined experimentally in the field at points $\mathrm{P}-1-\mathrm{P}-38$ and percentages of grain size fractions

\begin{tabular}{|c|c|c|c|c|c|c|c|c|}
\hline $\begin{array}{c}\text { Grain size } \\
{[\mathrm{mm}]}\end{array}$ & $<0.063$ & 0.063 & 0.125 & 0.25 & 0.5 & 1.0 & 2.0 & 20 \\
\hline$r^{*}$ & -0.4924 & -0.4971 & -0.5188 & -0.3878 & 0.3887 & 0.5229 & 0.6331 & 0.7170 \\
\hline$p^{* *}$ & 0.002 & 0.001 & 0.001 & 0.016 & 0.016 & 0.001 & 0.000 & 0.000 \\
\hline
\end{tabular}

$*_{r}$ - correlation coefficient; $* * p-$ significance level

The correlations investigated are:

Statistically significant $(\alpha \leq 0.05$ and $\alpha \leq 0.01)$,

Moderate for grain size $<0.063,0.063,0.25,0.5 \mathrm{~mm}$,

Strong for $0.125,1.0,2.0,20.0 \mathrm{~mm}$.

Soil grain sizes $<0.063-0.25 \mathrm{~mm}$ show negative correlations with hydraulic conductivity. With the rise in the content of dust-clay fraction and fine sand, the values of 
correlation coefficients of the samples decrease, and the strongest dependence is observed for $0.125 \mathrm{~mm}$ fraction. Coarse-grained fractions $(0.5-20.0 \mathrm{~mm})$ have positive linear correlations with hydraulic conductivity. As a result, the presence of coarsegrained fractions, particularly gravel with $d_{i}>2.0 \mathrm{~mm}$ causes a gradual rise in $k_{f}$ values in the soils under investigation.

Linear correlations between the hydraulic conductivity of all the analysed samples and the equivalent grain diameters $\left(d_{i}\right)$ of the soils studied are statistically significant at very low significance levels $(p=0.000)$, positive and very high (Table 2 ).

Table 2

Linear correlation coefficients, arithmetic means and standard deviations between soil hydraulic conductivity determined experimentally in the field at sites P-1-P-38 and $d_{i}, p=0.000$

\begin{tabular}{|c|c|c|c|c|c|c|c|c|c|c|}
\hline$d_{i}$ & $d_{10}$ & $d_{17}$ & $d_{20}$ & $d_{30}$ & $d_{40}$ & $d_{50}$ & $d_{60}$ & $d_{70}$ & $d_{80}$ & $d_{90}$ \\
\hline$r$ & 0.8169 & 0.8189 & 0.7983 & 0.7740 & 0.8018 & 0.8041 & 0.7843 & 0.7518 & 0.7190 & 0.6623 \\
\hline $\bar{x}$ & 0.26263 & 0.31039 & 0.33632 & 0.39803 & 0.46724 & 0.55158 & 0.67737 & 0.84974 & 1.24618 & 2.23184 \\
\hline$s$ & 0.09060 & 0.11265 & 0.12673 & 0.16536 & 0.23227 & 0.34584 & 0.57020 & 0.86163 & 1.63650 & 3.03714 \\
\hline
\end{tabular}

The strongest correlations occur between hydraulic conductivity and equivalent grain diameters $d_{10}$ and $d_{17}$. Therefore, their high correlations are $r=0.8169$ for $d_{10}$ and $r=0.8189$ for $d_{17}$. The lowest correlation coefficient $r=0.6623$ was observed for diameter $d_{90}$.

Thus, equivalent diameters $d_{10}$ and $d_{17}$ determine, to a large extent, the value of hydraulic conductivity, and consequently the discharge and the specific discharge. This is why previous studies of sands, including those by Hazen, Schlichter or Zauerbrey, use chiefly effective diameters $d_{10}$ and $d_{17}$ in defined formulas (Ishaku et al. [2], Alyamani and Şen [3]).

Figure 2 presents scatter curves of soil hydraulic conductivity for P-1-P-38 in relation to effective grain diameters $d_{10}-d_{90}$, which reflect their characteristic shapes. The plots demonstrate that hydraulic conductivity rises proportionally to the rise in effective diameter $d_{i}$.

Linear correlation coefficients $(r)$ between hydraulic conductivity of soils

\begin{tabular}{|l|c|c|}
\hline \multicolumn{1}{|c|}{ Parameter } & $r$ & $p$ \\
\hline Depth of sample collection & -0.3936 & 0.015 \\
\hline Distance from contemporary river channel & -0.4024 & 0.012 \\
\hline Distance from former channel & 0.2017 & 0.225 \\
\hline
\end{tabular}


Table 3 presents results of linear correlation analysis between hydraulic conductivity for all the samples analysed (P-1-P-38) and three spatial parameters defining the location of measurement sites, i.e., their distance from the contemporary Odra river channel, distance from the old channel dating back to the 13th century (Brose [4]) and the depth of sample collection in relation to terrain datum. The calculated correlations are negative and moderate, they are significant $(p<0.05)$ only for the relationship between hydraulic conductivity and distances from particular river channels. Hydraulic conductivity decreases with the increase in the depth of soil and the distance from the Odra channel but the dependence on the distance from the river is slightly stronger. The values of hydraulic conductivity rise with the growth in the distance from the former Odra river channel, as compared to the contemporary one, but this relation is weak and statistically insignificant.
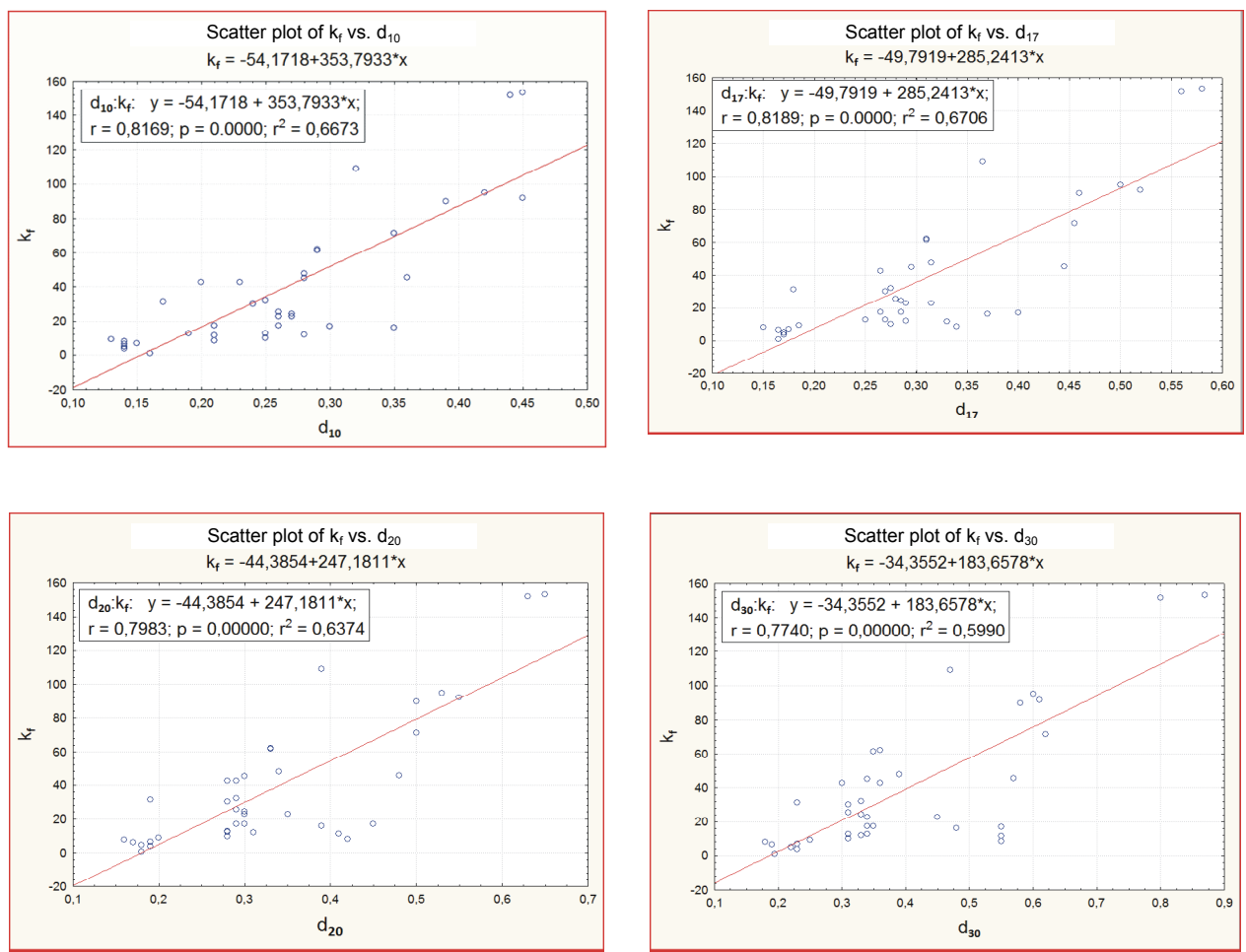

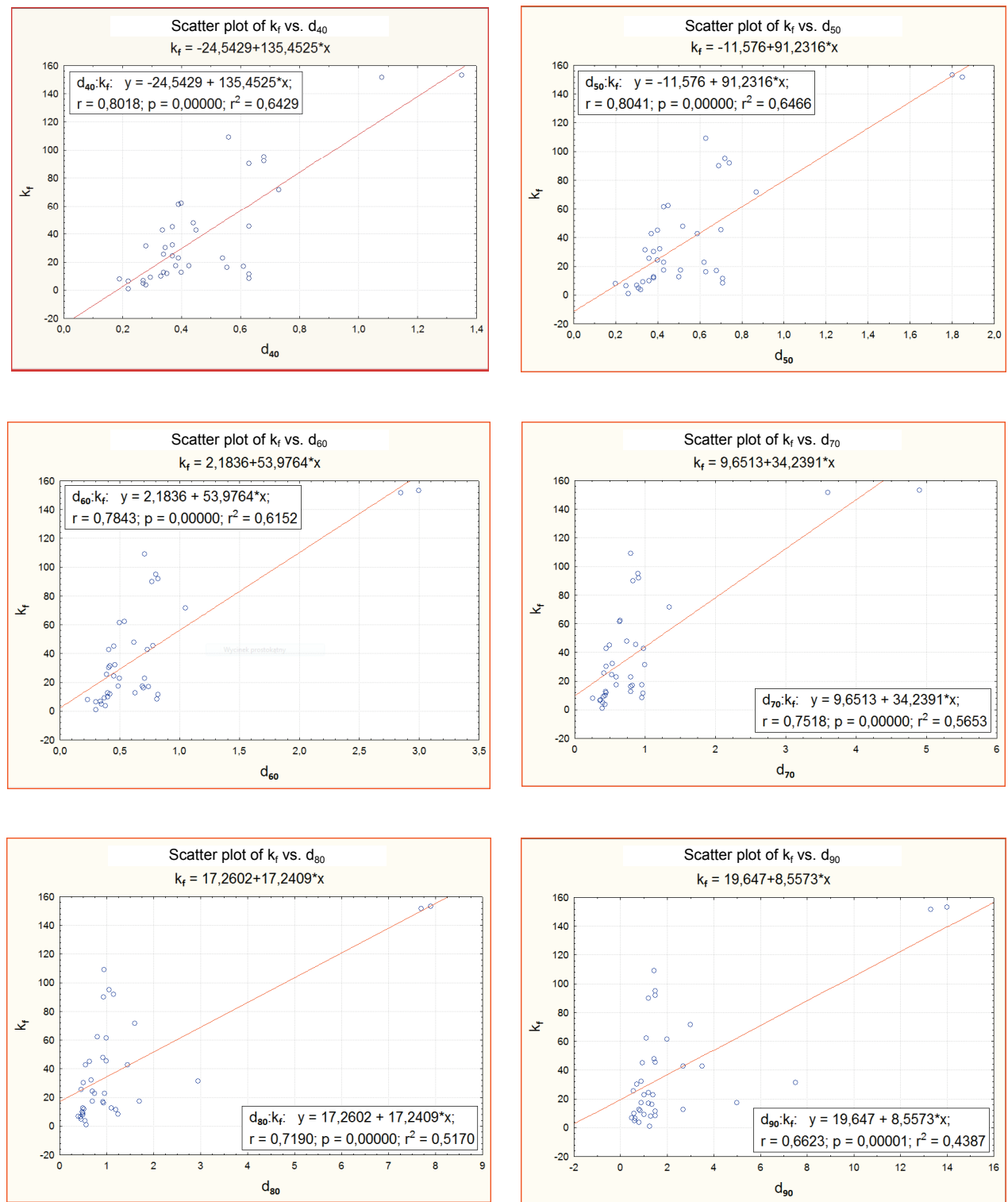

Fig. 2. Scatter plots of hydraulic conductivity $k_{f}$ vs. $d_{10}-d_{90}$

In order to define the parameter which has the strongest influence on hydraulic conductivity, multiple regression analysis was performed (Table 4). The independent variables were spatial parameters most correlated with hydraulic conductivity (depth of the analysed soil samples and their distance from the contemporary river channel) 
and the grain-size factor; diameter $d_{17}$ was chosen from among the grain-size parameters under study in view of its highest correlation coefficient with hydraulic conductivity. The results of correlations between hydraulic conductivity values and the chosen parameters are shown in Table 4.

Table 4

Results of multiple regression analysis of relationships between hydraulic conductivity, spatial parameters and grain size factor

\begin{tabular}{|c|c|c|c|c|}
\hline & \multirow{3}{*}{$\begin{array}{c}\text { Value } \\
-28.93 \\
\end{array}$} & \multirow{3}{*}{$\begin{array}{c}\text { Standard error } \\
18.29 \\
\end{array}$} & \multirow{3}{*}{$\begin{array}{c}p \\
0.1228 \\
\end{array}$} \\
\hline & & & & \\
\hline Parameter & $b_{0}$ & & & \\
\hline \multirow{2}{*}{$d_{17}$} & $b_{1}$ & 259.9 & 37.27 & \multirow{2}{*}{$4.8 \cdot 10^{-8}$} \\
\hline & $b_{1}^{*}$ & 0.7463 & 0.1070 & \\
\hline \multirow{2}{*}{$\begin{array}{l}\text { Depth of sample } \\
\text { collection }\end{array}$} & $b_{2}$ & -10.52 & 19.69 & \multirow{2}{*}{0.5968} \\
\hline & $b_{2}{ }^{*}$ & -0.0554 & 0.1037 & \\
\hline \multirow{2}{*}{$\begin{array}{l}\text { Distance from con- } \\
\text { temporary channel }\end{array}$} & $b_{3}$ & -0.0052 & 0.0032 & \multirow{2}{*}{0.1132} \\
\hline & $b_{3}{ }^{*}$ & -0.1616 & 0.0994 & \\
\hline \multicolumn{5}{|c|}{ Statistical coefficients } \\
\hline$R$ & $R^{2}$ & $R^{2}$ corrected & $p$ & $S$ \\
\hline 0.8354 & 0.6979 & 0.6713 & $5.84 \cdot 10^{-9}$ & 22.498 \\
\hline
\end{tabular}

The values of standardized coefficients $b^{*}$ demonstrate that the correlations between hydraulic conductivity, depth of soil sample collection and the distance of measurement sites from the Odra are very weak (statistically insignificant) and the values of hydraulic conductivity decrease with their rise. In contrast, the influence of diameter $d_{17}$ on hydraulic conductivity is dominant - hydraulic conductivity values increase with the rise in diameter $d_{17}$, and this dependence has been defined with very high probability $\left(p=4.8 \cdot 10^{-8}\right.$ ). The values of determination coefficient $R^{2}$ and the corrected $R^{2}$ indicate that the dependence described with the multiple regression equation (Table 4) accounts for almost $70 \%$ of variations in hydraulic conductivity of the soils studied and the grain-size factor $\left(d_{17}\right)$ is dominant here. The remaining factors influencing hydraulic conductivity of the soils being studied in the Odra valley account for hardly $30 \%$ of its variations.

The multiple regression equation obtained assumes the following form

$$
k_{f}=b_{0}+b_{1} \cdot\left(d_{17}\right)+b_{2} \cdot(\text { depth of sample collection })+b_{3}
$$

(distance from contemporary channel).

Table 5 contains results of linear correlation between hydraulic conductivity values obtained with laboratory methods, i.e., on ITB ZW-K2 apparatus and Kamieński tubes and soil gradation analysis. 
Linear correlation coefficients between hydraulic conductivity of soils, determined experimentally on ITB ZWk-2 apparatus at sites P-1-P-38, and percentages of grain size fractions

\begin{tabular}{|c|c|c|c|c|c|c|c|c|}
\hline $\begin{array}{c}\text { Grain size } \\
{[\mathrm{mm}]}\end{array}$ & $<0.063$ & 0.063 & 0.125 & 0.25 & 0.5 & 1.0 & 2.0 & 20 \\
\hline$r^{*}$ & -0.4034 & -0.3801 & -0.3956 & -0.2133 & 0.5400 & 0.2918 & -0.0238 & 0.0167 \\
\hline$p^{* *}$ & 0.012 & 0.019 & 0.014 & 0.199 & 0.001 & 0.075 & 0.887 & 0.921 \\
\hline
\end{tabular}

$* r-$ correlation coefficient, ${ }^{* *} p-$ significance level

The statistical analyses performed have revealed that correlations are statistically significant ( $\alpha \leq 0.05$ and $\alpha \leq 0.01$ ) and moderate for grain sizes $<0.063-0.25 \mathrm{~mm}$, and high for $d_{i}=0.5 \mathrm{~mm}$. This dependence shows directly that only soil fractions of $0.5-1.0 \mathrm{~mm}$ correlate positively with the hydraulic conductivity values obtained. A rise in the content of sand fraction results in a relative rise in the hydraulic conductivity of the analysed samples. However, the strongest correlation, with a statistically significant level $p=0.001$, is observed for $0.5 \mathrm{~mm}$ fraction. Coarse-grained gravel fractions $(2.0-20.0 \mathrm{~mm})$ display relatively weak linear correlations with hydraulic conductivity.

Linear correlation coefficients between hydraulic conductivity of soils, determined experimentally in Kamienski tubes at sites P-1-P-38, and percentages of particular grain-size fractions

\begin{tabular}{|c|c|c|c|c|c|c|c|c|}
\hline $\begin{array}{c}\text { Grain size } \\
{[\mathrm{mm}]}\end{array}$ & $<0.063$ & 0.063 & 0.125 & 0.25 & 0.5 & 1.0 & 2.0 & 20 \\
\hline$r^{*}$ & -0.3917 & -0.3863 & -0.4323 & -0.1192 & 0.4460 & 0.1941 & 0.0567 & 0.1867 \\
\hline$p^{* *}$ & 0.015 & 0.017 & 0.007 & 0.476 & 0.005 & 0.243 & 0.735 & 0.262 \\
\hline
\end{tabular}

${ }^{*} r$ - correlation coefficient; ${ }^{* *} p-$ significance level

The calculated correlations are statistically significant $(\alpha \leq 0.05)$ or moderate for grain sizes of $<0.063-0.125,0.5 \mathrm{~mm}$. Dust-clay and sand fractions up to $0.25 \mathrm{~mm}$ determine negative values of hydraulic conductivity - soil permeability will decrease with the rise in the percentage of particular fractions. The correlation between $k_{f}$ value and $0.5 \mathrm{~mm}$ fraction (with significance level $p=0.005$ ) is clearly distinct from the remaining hydraulic conductivity values, as the rise in the content of this fraction will lead to the rise in hydraulic conductivity. 


\section{CONCLUSIONS}

The results obtained from the analyses performed enabled the following conclusions to be drawn:

Correlations between the hydraulic conductivity of soils labelled as P-1-P-38 and the effective diameters $d_{10}$ and $d_{17}$ ( $r=0.8169$ and $r=0.8189$, respectively) are highly significant with a relatively high significance level $p=0.0000$.

Dependences between soil hydraulic conductivity determined with field and laboratory methods and the percentage of $d_{i}$ fraction $(<0.063-0.25 \mathrm{~mm})$ show negative correlations, so they will reduce permeability values.

Analyses conducted with ITB ZW-K2 apparatus and Kamieński tubes demonstrated that the presence of $0.5 \mathrm{~mm}$ fraction will cause a rise in $k_{f}$ value at significance levels $p=0.005$ and $p=0.001$.

It was ascertained, as a result of multiple regression analysis, that the growth in the distance from the former Odra river channel towards its contemporary course will cause a slight rise in the hydraulic conductivity of non-cohesive soils.

\section{REFERENCES}

[1] Rojna A., BŁAszczyk D., Badanie wspótczynnika filtracji gruntów, wyd. Zeszyty Naukowe Uniwersytetu Zielonogórskiego, Inżynieria Środowiska, 2010, nr 138 (18), 32-38.

[2] ISHAKU J.M., GAdZAMA E.W., Kaigama U., Evaluation of empirical formulae for the determination of hydraulic conductivity based on grain-size analysis, Journal of Geology and Mining Research, 2011, Vol. 3(4), 105-113,

[3] AlyAmani M.S., ŞEN Z., Determination of hydraulic conductivity from complete grain- size distribution curves, Ground Water, 1993, 31, 551-555.

[4] Brose F., Genese holozäner Flußauen, dargestellt am Beispiel des unteren Odertales, wyd. Landesamt für Geowissenschaften und Rohstoffe Brandenburg 1/98, Brandenburgische Geowissenschaftlische Beiträge, Kleinmachnow, 1998, 7-13.

[5] StatSoft, Inc. (2010). STATISTICA (data analysis software system), version 9.1. www.statsoft.com 